\title{
Adhering grains and surface features on two Itokawa particles
}

\author{
E. Dobrică ${ }^{*}$ and R. C. Ogliore ${ }^{2}$
}

\begin{abstract}
We investigated the surface texture and chemical compositions of two $\sim 40-\mu \mathrm{m}$ particles returned from the surface regolith of asteroid Itokawa (RB-DQ04-0062 and RB-DQ04-0091) by the Japan Aerospace Exploration Agency's Hayabusa mission. We identified splash melts, surface blistering, and many small adhering particles. Seven focused ion beam sections were extracted from both Itokawa particles, targeting one splash melt and ten adhering particles to investigate their composition and provenance and the role of micrometeoroid impacts on Itokawa's surface. Based on the particle's structure, mineralogy, and interface between the adhering particle and host grain, we identified lithic fragments and particles deposited by impact. These have morphologies and compositions consistent with impact-generated deposits: two have morphologies and compositions that are consistent with impact-generated silica glass, and one was a Ni-free, metallic Fe, and S-rich assemblage that was likely generated by vapor recondensation during a micrometeoroid impact. This study shows that, even though its regolith is young, micrometeoroid impacts have altered the regolith of asteroid Itokawa.
\end{abstract}

Keywords: Asteroid, Micrometeoroid, Regolith, Space weathering

\section{Introduction}

Analyses of returned samples provide the opportunity to overcome the constraints imposed by remote-sensing and in situ studies of bodies in our solar system (Gaffey et al. 1989). Recently, the Hayabusa mission collected surface regolith samples (unconsolidated surface deposits) from the S-type near-Earth asteroid 25143 Itokawa and returned them to Earth for laboratory study. More than 1500 particles were identified, ranging in size from 3 to $180 \mu \mathrm{m}$ (Nakamura et al. 2011). Mineralogical and oxygen isotope analyses revealed that the composition of the particles is consistent with LL5-6 chondrite composition (Nakamura et al. 2011; Yurimoto et al. 2011; Nakashima et al. 2013). The return of the Hayabusa samples has provided us the strongest evidence that the most common meteorites in our collections, the ordinary chondrites, are derived from the S-type asteroids (Nakamura et al. 2011; Thompson et al. 2014). The Hayabusa samples are the second extraterrestrial regolith, after the lunar samples, which can give us information about surface modification

\footnotetext{
* Correspondence: edobrica@unm.edu

${ }^{1}$ Department of Earth and Planetary Sciences MSC03-2040, 1 University of

New Mexico, Albuquerque, NM 87131-0001, USA

Full list of author information is available at the end of the article
}

processes on airless bodies such as energetic particle irradiation and micrometeoroid impacts. The resulting optical, physical, and chemical effects of these processes are collectively known as space weathering (Clark et al. 2002; Thompson et al. 2014). Understanding space weathering on asteroids can connect remote-sensing observations with laboratory studies and can lead to a better understanding of the evolution of asteroid soils (e.g. Clark et al. 2002). Micrometeoroid impacts, which are the most important agents of space weathering on the Moon, cause melting, vaporization, and recondensation of the target and projectile (Thompson et al. 2014). Microcraters, shock lamellae, and splash features that were formed by micrometeoroid impacts have been found on the surfaces of regolith grains from Itokawa, although previous studies concluded that they are rare compared to these features found on lunar regolith (Nakamura 2012). Solar wind produced radiation-damaged rims on the surfaces of Itokawa particles, first found in the lunar soil (Keller and McKay 1997), imply that space weathering due to solar-wind irradiation is also significant on asteroids (Noguchi et al. 2014; Thompson et al. 2014). Small circular surface bubbles or "blisters" on Itokawa particles provide evidence of solar-wind irradiation (Matsumoto et al. 2014) on
望 Springer

(c) 2016 Dobrică and Ogliore. Open Access This article is distributed under the terms of the Creative Commons Attribution 4.0 International License (http://creativecommons.org/licenses/by/4.0/), which permits unrestricted use, distribution, and reproduction in any medium, provided you give appropriate credit to the original author(s) and the source, provide a link to the Creative Commons license, and indicate if changes were made. 
timescales of hundreds to tens of thousands of years (Assonov et al. 1998). The low surface gravity of asteroid Itokawa $\left(\sim 10^{-4} \mathrm{~m} / \mathrm{s}^{2}\right)$ compared to the Moon $\left(1.6 \mathrm{~m} / \mathrm{s}^{2}\right)$ may cause micrometeoroid impact residue to be distributed over large areas (Hirata et al. 2009). Evidence for this effect on the surfaces of Itokawa particles would be impact-ejected particles from the target (Itokawa) that traveled far from the impact site. Previous studies suggest that Itokawa dust particles lacking visible microcraters on their surfaces might have still experienced shock metamorphism and were involved in collisional fragmentation that resulted in the formation of regolith (Langenhorst et al. 2014). We analyzed the surfaces of two Itokawa particles using high-resolution techniques to investigate the nature of solar-wind blisters, splash-melt residues, and small adhering particles and the role of micrometeoroid impacts. The goal of this study is to characterize and understand the formation of surface microstructures and adhering particles. We assess whether the adhering particles are contamination from the laboratory or spacecraft, debris from a foreign impactor (micrometeoroid), debris from the target (Itokawa), or lithic fragments resulting from fracturing of regolith particles.

\section{Samples and methods}

Two Itokawa particles: RB-DQ04-0062 (which we named "Naoko") and RB-DQ04-0091 (which we named "Mizuki") were allocated by Japan Aerospace Exploration Agency (JAXA). The particles were transferred from their JAXA shipping containers to an aluminum scanning electron microscopy (SEM) stub coated in Post-It note glue using a Sutter micromanipulator and a tungsten needle. We used a Hitachi S-4800 field emission scanning electron microscope at the University of Hawaii's Biological Electron Microscope Facility to do preliminary imaging of both surfaces of the Hayabusa particles. We used a low accelerating voltage $(2 \mathrm{kV})$ to have the highest sensitivity to surface features. Considering that even low$\mathrm{kV}$ secondary electron microscopy has surface sensitivity and spatial resolution that is limited by the physics of the interactions between the incident electron beam and the sample, we used a helium ion microscope (HIM) for more detailed observations of the particles' surfaces (Ward et al. 2007). The helium ion microscope can provide images with higher spatial resolution and more surface-specific imaging than a traditional SEM (Ward et al. 2007). We used a Zeiss helium ion microscope (HIM) at the Pacific Northwest National Laboratory. This microscope has a primary $\mathrm{He}^{+}$beam of $30 \mathrm{kV}$, a small beam size $(<0.1 \mathrm{~nm})$, excellent spatial resolution $(<0.4 \mathrm{~nm})$, and extreme surface sensitivity, making it ideally suited for imaging small, shallow surface features. The samples were first imaged in the HIM without any conductive coating, but charging degraded the image quality significantly. We then coated the samples with a thin layer $(\sim 2-3 \mathrm{~nm})$ of $C$, which was sufficient to eliminate charging.

Seven transmission electron microscope (TEM) sections (up to $\sim 6 \mu \mathrm{m}$ in length and $\sim 2 \mu \mathrm{m}$ in width) of selected regions containing one splash melt and ten adhering surface particles were prepared by the in situ-focused ion beam (FIB) technique using a FEI Quanta 3D FEG-SEM/ FIB instrument at the University of New Mexico. Prior to the preparation of the FIB sections, we tried to remove the grains using a tungsten needle inside the FEG-SEM instrument. However, this technique was not successful, because the adhering particles were well attached to the host particles. A platinum protective layer $(2 \mu \mathrm{m}$ in thickness and $2 \mu \mathrm{m}$ in width) was deposited using the ion beam on top of the region of interest to avoid ion beam damage during the FIB sample preparation. Each section was transferred to $\mathrm{Cu}$ TEM grids with an Omniprobe $200 \mathrm{mi}$ cromanipulator. The final ion milling of the $2-\mu \mathrm{m}$ thick section to electron transparency was carried out with the sample attached to the $\mathrm{Cu}$ TEM grid. Ion beam conditions for the final thinning stages varied from $5-30 \mathrm{kV}$ with a current of $10 \mathrm{pA}-5 \mathrm{nA}$.

Each FIB-TEM specimen was studied using a variety of TEM techniques at the University of New Mexico, including bright-field TEM imaging, high-angle annular dark-field scanning transmission electron microscopy (HAADFSTEM), and energy-dispersive X-ray spectroscopy (EDS) analyses. All imaging and analyses were carried out at $200 \mathrm{kV}$ on JEOL 2010F FEGTEM/Scanning TEM equipped with a GATAN GIF 2000 system. In situ energy dispersive X-ray analyses were obtained using an Oxford ISIS 200 EDS system, with an Oxford Pentafet ultrathin window EDS detector. The Cliff-Lorimer thin-film approximation was used for quantification of EDS data using theoretically determined k-factors.

\section{Results and discussion}

The Itokawa particles analyzed in this study (RBDQ04-0062-Naoko and RB-DQ04-0091-Mizuki) are both irregular, angular grains with the longest dimension $\sim 40 \mu \mathrm{m}$ in length (Fig. 1). We identified only FeO-rich olivine $\left(\sim \mathrm{Fa}_{25}\right)$ in the main mass of Naoko (Fig. 1a). In the particle Mizuki (Fig. 1b), we identified plagioclase $\left(\mathrm{An}_{0-18} \mathrm{Ab}_{75-95}\right.$, no exsolution or twinning), $\mathrm{Al}_{2} \mathrm{O}_{3}$-rich silica glass (22 wt.\% $\mathrm{Al}_{2} \mathrm{O}_{3}$ and 78 wt.\% $\mathrm{SiO}_{2}$, the $\mathrm{Al} / \mathrm{Si}$ ratio is consistent with feldspar), and $\mathrm{FeO}$-rich olivine $\left(\sim \mathrm{Fa}_{25}\right)$.

Different types of adhering particles and surface features were identified on both Itokawa particles (Figs. 2 and 3). We extracted seven FIB sections from both Itokawa particles: three FIB sections from Naoko (Figs. 4a, e and 5) and four from Mizuki (Fig. 4b-d, f; Table 1). We have targeted one splash melt and ten adhering particles (summary of the adhering grains, Table 2). 

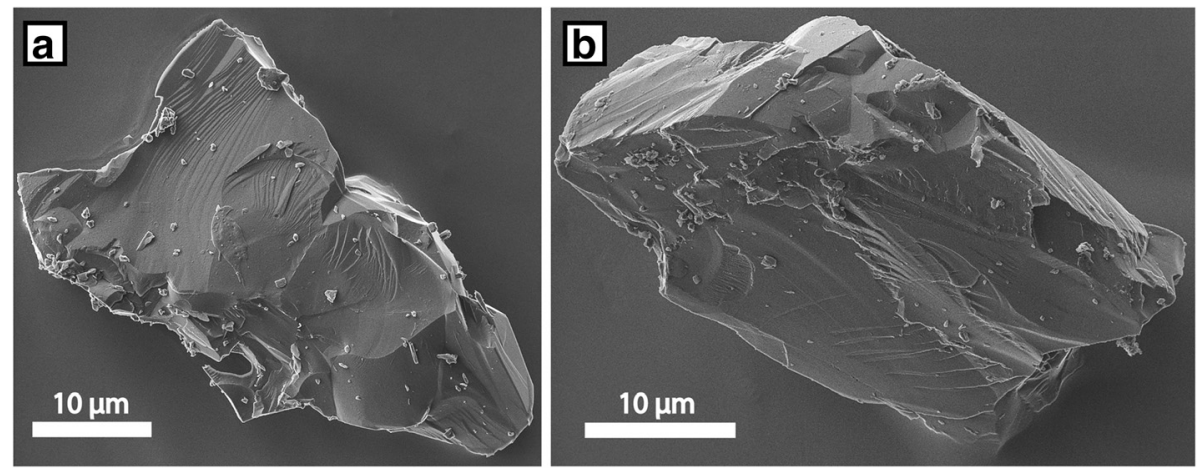

Fig. 1 Scanning helium ion microscope images of the two Itokawa particles (a - RB-DQ04-0062-Naoko and b - RB-DQ04-0091-Mizuki) analyzed during this study

The surface features and adhering particles we investigated are described in detail below. Similar features are described together, followed by our interpretation of their origin.

Splash melt: We identified two large splash melt features. One is a thin melt, $\sim 4 \mu \mathrm{m}$ in diameter, on Mizuki (Fig. 2b). The largest splash melt we observed is slightly thicker, is irregular in shape $(\sim 7 \mu \mathrm{m}$ in length and $\sim 2.5 \mu \mathrm{m}$ in width), and sits on top of a FeO-rich olivine $\left(\mathrm{Fa}_{25}\right)$ on Naoko (Fig. 2a). The surface of this splash melt is vesicular. The surface of the olivine beneath the splash melt contains no blisters compared to the adjacent areas (Fig. 5b, lumps at the boundary between the platinum protective layer and the olivine grain). No Fe-rich nanoparticle-bearing rims were identified; however, the FIB section was too thick (150-200 nm) for high-resolution imaging. Several adhering particles (up to $0.5 \mu \mathrm{m}$ in size) are observed on top of this splash melt. The splash melt in the FIB section is about $3.5 \mu \mathrm{m}$ in length and the thickness varies between $65 \mathrm{~nm}$ and $175 \mathrm{~nm}$. It is composed of a glassy, vesicular, $\mathrm{SiO}_{2}$-rich material with variable chemical composition (Fig. 5). Figure 6 shows the chemical composition of the splash melt and the adhering particle. The adhering particle on top of the splash melt (Fig. 5) is $\mathrm{SiO}_{2}$-rich amorphous material (74 wt.\% $\mathrm{SiO}_{2}$ ) containing significant amounts of $\mathrm{Al}_{2} \mathrm{O}_{3}$ (23.8 wt.\% $\mathrm{Al}_{2} \mathrm{O}_{3}$ ) and $\mathrm{CaO}$ (2.2 wt.\% $\mathrm{CaO})$. The splash melt contains variable amounts of $\mathrm{CaO}$ (0.9-8.7 wt.\%), $\mathrm{Al}_{2} \mathrm{O}_{3}$ (0-3.4 wt.\%), $\mathrm{MgO}$ (28.6-38.3 wt.\%), and $\mathrm{FeO}$ (15.8-22.9 wt.\%) (Figs. 5 and 6), and shows a spatial gradient in chemical composition between the host grain (Fig. 6, diamonds with no $\mathrm{Al}_{2} \mathrm{O}_{3}$ and $\mathrm{CaO}$ ) and the top of the splash melt (Fig. 6, diamonds with high $\mathrm{Al}_{2} \mathrm{O}_{3}$ and $\mathrm{CaO}$ ). This indicates that the splash melt cooled slowly enough for its chemical composition to equilibrate somewhat with the host olivine grain.

Additionally, we identified smaller splash melt features. Small circular or ellipsoidal melt deposits decorated the surfaces of both Itokawa particles (Fig. 2c, left of the adhering particles $\sim 650 \mathrm{~nm}$ in length). A ring- droplet melt feature about $200 \mathrm{~nm}$ in size was also observed (Fig. 2f).

Other surface features: On the surfaces of both Itokawa particles, we also observed fracturing, abrasion-like features, and blisters (Fig. 2). Olivine on the host grain shows common conchoidal fracturing (Figs. 1a and 2d). One abrasion-like feature was identified on the surface of Mizuki at the base of an adhering particle of $\mathrm{Ca}$ phosphate $(1.1 \times 2.4 \mu \mathrm{m}$ in size, Figs. $2 \mathrm{c}$ and $4 \mathrm{~d})$. The underlying albite is harder than the Ca-phosphate, so it is likely that this feature formed when the Ca-phosphate was partially molten (likely ejecta from a micrometeoroid impact), and left trails of melt behind as it landed on the plagioclase and slid to a stop.

We identified severe surface blistering on some faces (Fig. 2e, g), and moderate blistering or no blistering at all (Fig. 3f) on others. They are heterogeneously distributed across the surface: a highly blistered area could be found adjacent to a non-blistered area. We observed blistering covering areas of a conchoidal fracture (Figs. $2 \mathrm{~d}$ and $3 \mathrm{~d}$ ), implying that the area was exposed to the solar wind for thousands of years after the fracture. The average diameter of an individual blister is about $30 \mathrm{~nm}$ and they vary in size by a factor of $\sim 2$. In highly blistered areas, we occasionally observed open/burst blisters (Fig. 2e).

No unambiguous impact craters were identified during this study. Crater-like features were observed only in heavily blistered regions, and are likely burst blisters resulting from solar-wind irradiation of $>10^{19}$ ions $/ \mathrm{cm}^{2}$ (Kaletta 1980).

Two of the FIB sections contain amorphous rims (Figs. 4e and 5). The thickness of the amorphous rims varies between $60 \mathrm{~nm}$ and $200 \mathrm{~nm}$. However, no Fe-rich nanoparticle-bearing rims were identified at the surface of the two Itokawa particles because the FIB sections were too thick (150-200 nm) for high-resolution imaging.

Impact residue: One adhering particle is composed of FeO-rich olivine $\left(\sim \mathrm{Fa}_{21}\right.$, Fig. $\left.4 \mathrm{e}\right)$ and shows fractures as well as a discernible gap between itself and its $\mathrm{Fa}_{25}$ olivine 

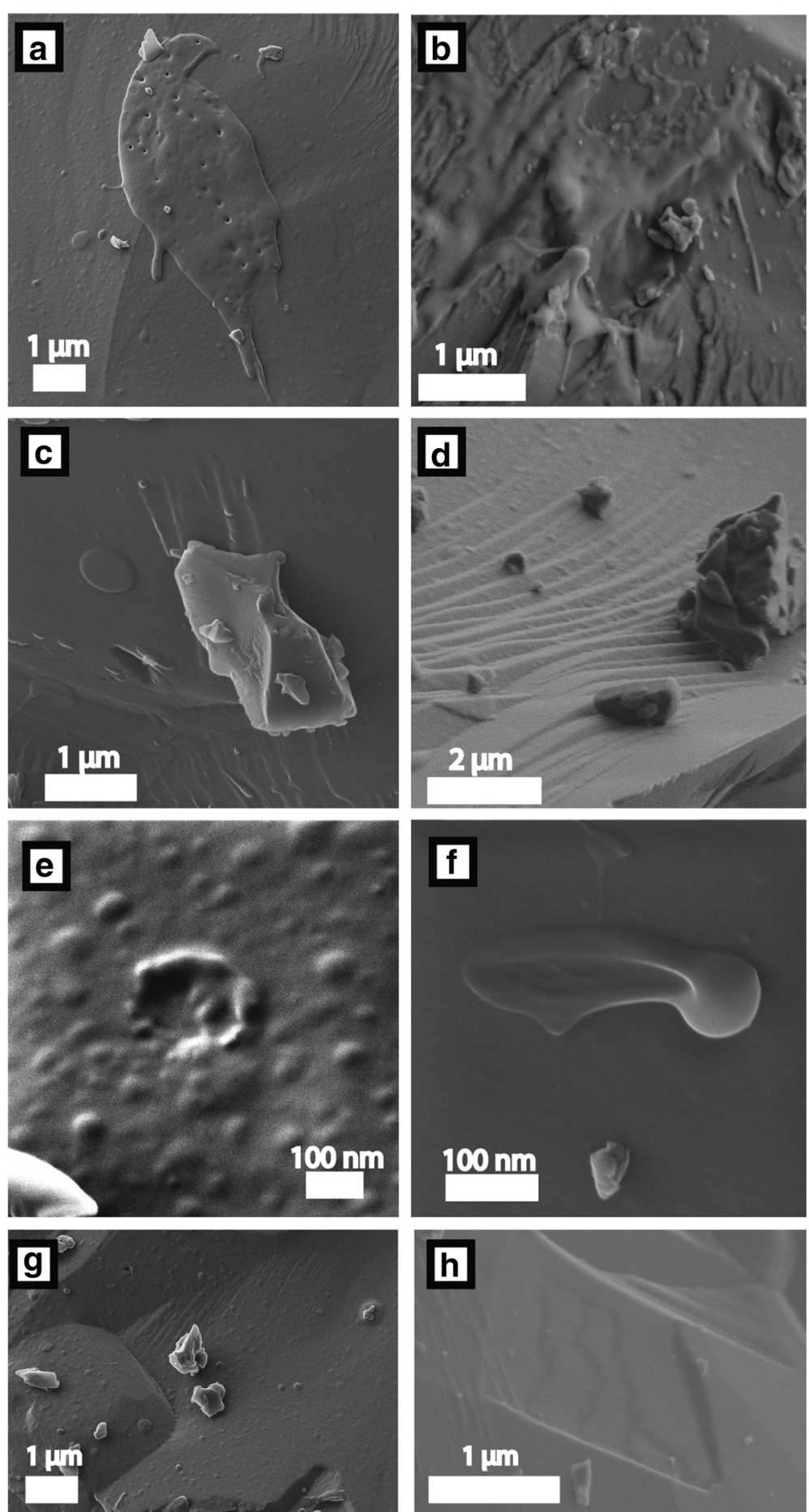

Fig. 2 Scanning helium ion $(\mathbf{a}, \mathbf{c}, \mathbf{e}-\mathbf{g})$ and secondary electron $(\mathbf{b}, \mathbf{d}, \mathbf{h})$ microscope images of different features identified on the surfaces of both Itokawa particles such as splash melts (a, b, f), abrasion features (c), and blistered and unblistered surfaces $(\mathbf{d}, \mathbf{e}, \mathbf{g}, \mathbf{h})$

host grain. The deformation features were probably produced by shock when this olivine grain was excavated from Itokawa during a micrometeoroid impact, considering that olivine easily deforms by dislocation glide (Langenhorst 2002).
Two porous adhering particles (with diameters of $500 \mathrm{~nm}$ and $1.5 \mu \mathrm{m}$ ) were analyzed by TEM (Fig. 3a, b). The morphologies of both particles are similar to a conglomerate of loosely bound melt droplets. The larger particle is composed of only amorphous $\mathrm{SiO}_{2}$ (Figs. 4b 

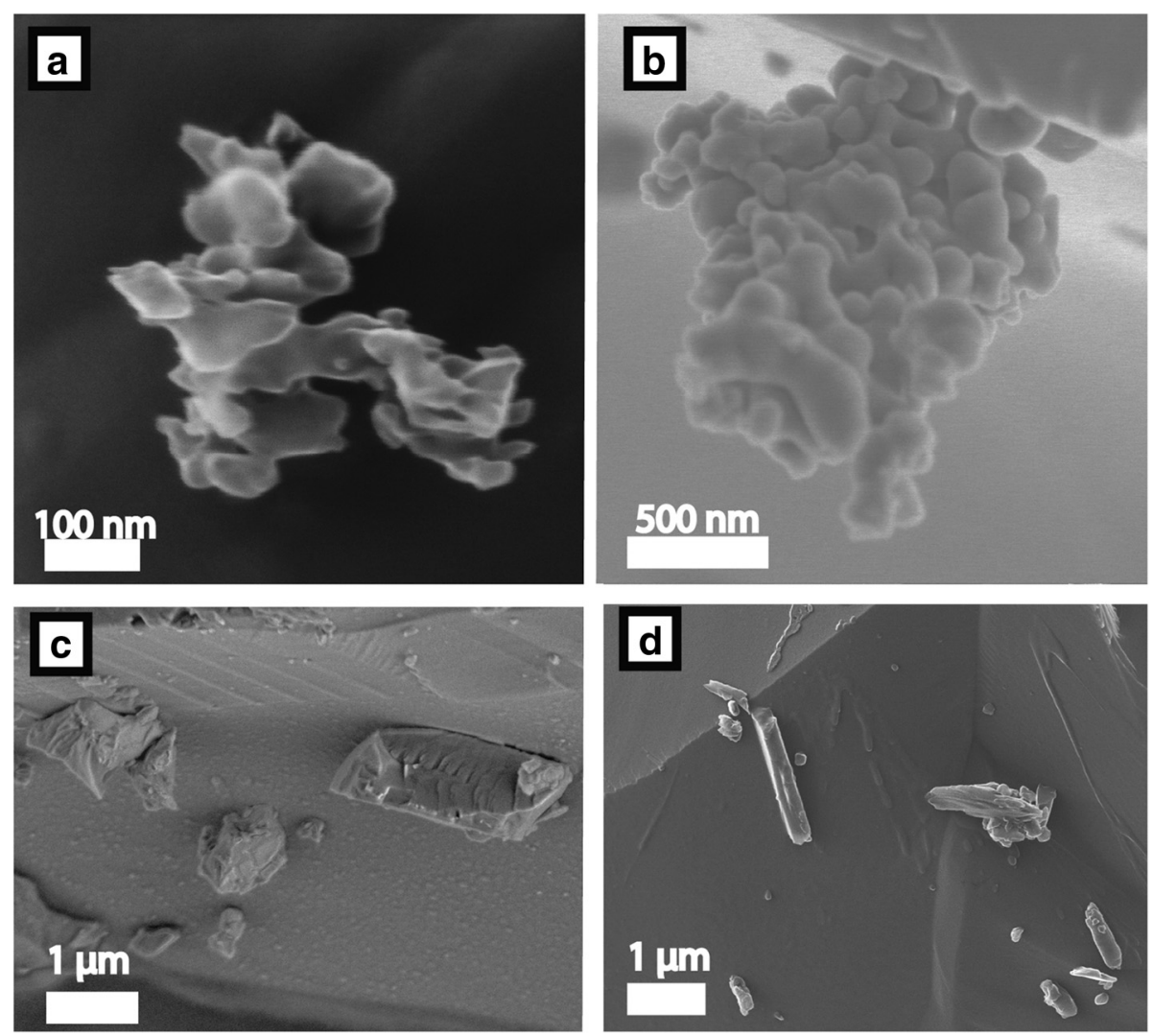

Fig. 3 Scanning helium ion $(\mathbf{a}, \mathbf{d})$ and secondary electron $(\mathbf{b}, \mathbf{c})$ microscope images of adhering particles, which are either irregular, fluffy (up to $1.3 \mu \mathrm{m}$ in length), or elongated, euhedral crystals (up to $1.9 \mu \mathrm{m}$ in length)

and 3b). The smaller particle is made of glassy $\mathrm{SiO}_{2}$ with variable amounts of $\mathrm{FeO}$ and $\mathrm{MgO}$ (Figs. 4e, 3a; Table 1). The region between the host grain and adhering grain likely suffered damage from the He ion beam.

About $1 \mu \mathrm{m}$ from the smaller $\mathrm{SiO}_{2}$ porous grain is an elongated $\mathrm{Fe}$ metal grain with $<0.5 \mathrm{wt} . \% \mathrm{Ni}$, capped with an amorphous S-rich material (Fig. 4e). The lack of $\mathrm{Ni}$ in this grain excludes the possibility that this grain is native kamacite, since Itokawa kamacite contains $~ 4 \mathrm{wt} . \%$ $\mathrm{Ni}$ (Nakamura et al. 2011).

We propose that the two porous $\mathrm{SiO}_{2}$ grains and metallic Fe particle are impact residue. They formed when a micrometeoroid impacted Itokawa, striking a region of Fe-bearing silicates and sulfides. The vapor plume from the impact, made primarily of atoms from the target, was mostly lost to space due to the low escape velocity of Itokawa $(\sim 0.2 \mathrm{~m} / \mathrm{s})$. We suggest that some of the vapor recondensed, first into $\mathrm{Ni}$-free metallic $\mathrm{Fe}$, then the silicon and oxygen into amorphous silica with a droplet-like texture.

Loosely attached local regolith: Plagioclase $\left(\mathrm{An}_{12} \mathrm{Ab}_{62}\right.$, Fig. 4f) was found sitting on top of plagioclase of similar composition, with a discernible gap between the adhering grains and the host grains. A polymineralic grain of troilite $(100 \times 135 \mathrm{~nm}$ in size $)$ and a glassy $\mathrm{SiO}_{2}$ rich material $\left(190 \times 200 \mathrm{~nm}\right.$ in size; with $60 \mathrm{wt} . \% \mathrm{SiO}_{2}$, 17.4 wt.\% $\mathrm{Al}_{2} \mathrm{O}_{3}, 11.9$ wt.\% $\mathrm{MgO}$, and 9.4 wt.\% $\mathrm{FeO}$ ) was found loosely attached to the host $\mathrm{Fa}_{25}$ host grain. Enstatite and an amorphous $\mathrm{C}$-rich grain $\left(\mathrm{En}_{73}\right.$, Fig. $\left.4 \mathrm{c}\right)$ were also found loosely attached to their host.

All of these loosely attached regolith grains are consistent with the mineralogy of Itokawa and LL4-6 chondrites. We conclude that these grains came into contact with their host grains during regolith gardening and attached via van der Waals forces.

Lithic fragments: We identified an elongated chromite grain with 8.5 wt.\% $\mathrm{Al}_{2} \mathrm{O}_{3}$ (Figs. $3 \mathrm{~b}$ and $4 \mathrm{a}$ ) that has no discernible gap between the adhering grain and host olivine $\left(\mathrm{Fa}_{25}\right)$. We suggest that this adhering grain is likely a lithic fragment that was uncovered during gardening and fracturing of surface regolith (this happened relatively recently because of the lack of solar-wind blistering on the host olivine grain). The $\sim 8.5 \mathrm{wt} . \%$ $\mathrm{Al}_{2} \mathrm{O}_{3}$ in the chromite is close to the 6.35 wt. $\% \mathrm{Al}_{2} \mathrm{O}_{3}$ found in other chromites from Itokawa (Nakamura et al. 2011). 


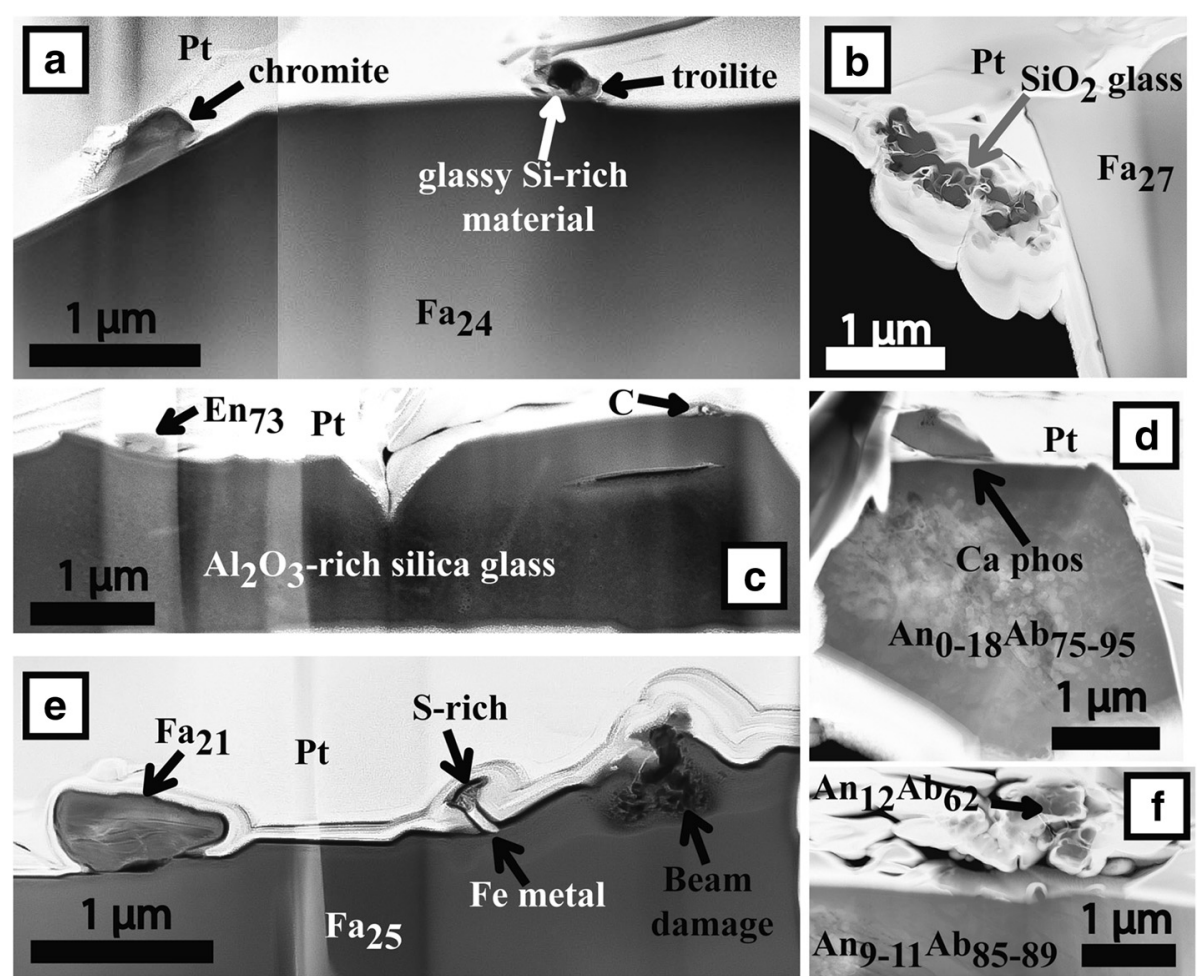

Fig. 4 Dark-field scanning transmission electron microscopy (STEM) images of the focused ion beam sections showing the mineralogy and the relationship between different types of adhering particles identified and the Itokawa particles (a, e - Naoko, RB-DQ04-0062; b-d, f - Mizuki, RB-DQ04-0091). En - low-Ca pyroxene, Fa - fayalite, Pt - platinum, Ca phos - calcium phosphate, An - anorthite, Ab - albite

\section{Conclusions}

In this study, we explored the texture and the chemical compositions of the surface features and adhering particles on the surfaces of the two Itokawa particles (RBDQ04-0062-Naoko and RB-DQ04-0091-Mizuki). A previous study by Nakamura (2012) showed that the surfaces of Hayabusa particles are shaped primarily by fractures, and adhering particles are mostly fragments of larger grains from Itokawa, with a smaller component of melt-splash glass and rounded silica-rich droplets. Our study supports previous suggestions that Hayabusa grains are highly fractured, indicative of active regolith gardening on Itokawa (Langenhorst et al. 2014). Using the high-resolution techniques of helium ion microscopy and TEM, we have shed insight onto the smallest surface features of the host grains as well as splash melt and the variable origin of the adhering particles.

The high variability in blistering on these particles, the scarcity of regions with a large number of burst blisters, and the observation that blistered regions can be separated from non-blistered regions by fractures implies that Itokawa regolith particles are fracturing on timescales similar to blister formation. Circular blisters form from a He fluence of about $10^{18} / \mathrm{cm}^{2}$ (Assonov et al. 1998), which is about thousands of years of solar wind He at 1 AU. Previous studies suggest that the regolith in
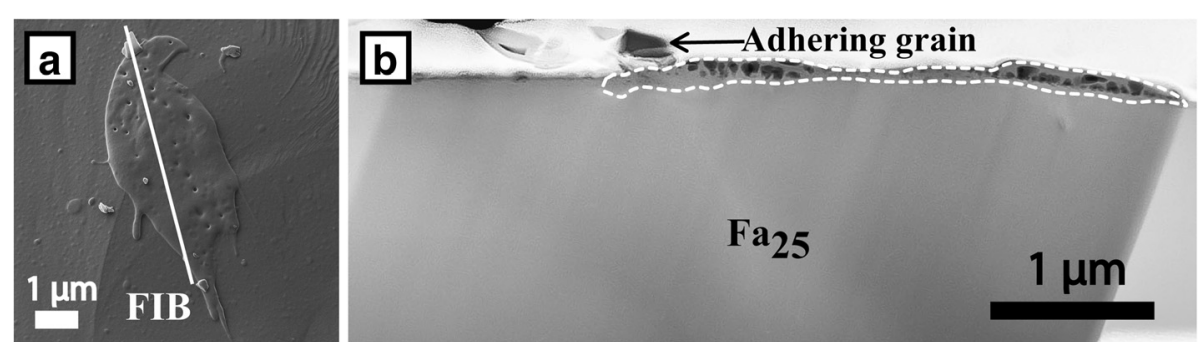

Fig. 5 Scanning helium ion microscope secondary electron image of a splash melt (a) in which we made the focused ion beam section (FIB; a white line) shown on the right ( $\mathbf{b}$ - dark-field scanning transmission electron microscopy image). The splash melt is found on top of a FeO-rich olivine grain ( $\mathrm{Fa}_{25}$, Fa fayalite). The surface of this splash melt is vesicular. The white dashed line outlines the splash melt 
Table 1 Major and minor element compositions of adhering and host grains (oxide wt.\%) obtained by energy dispersive X-ray spectroscopy (EDS)

\begin{tabular}{|c|c|c|c|c|c|c|c|c|c|c|c|c|c|}
\hline & \multicolumn{7}{|c|}{ Adhering grains } & \multicolumn{6}{|c|}{ Host grains } \\
\hline & $\begin{array}{l}\text { Chromite } \\
\text { Fig. } 4 a\end{array}$ & $\begin{array}{l}\text { Si-rich material } \\
\text { Fig. } 4 a\end{array}$ & $\begin{array}{l}\text { Adhering olivine } \\
\text { Fig. } 4 \mathrm{e}\end{array}$ & $\begin{array}{l}\text { Top of the } \\
\text { fluffy grain } \\
\text { Fig. } 4 \mathrm{e}\end{array}$ & $\begin{array}{l}\text { Bottom of the } \\
\text { fluffy grain } \\
\text { Fig. } 4 \mathrm{e}\end{array}$ & $\begin{array}{l}\text { Phosphate } \\
\text { Fig. } 4 d\end{array}$ & $\begin{array}{l}\text { Adhering grain } \\
\text { Fig. } 4 f\end{array}$ & Fig. $4 a$ & Fig. $4 b$ & Fig. $4 c$ & Fig. $4 d$ & Fig. $4 \mathrm{e}$ & Fig. $4 f$ \\
\hline $\mathrm{SiO}_{2}$ & 0.0 & 60.0 & 39.2 & 96.2 & 40.7 & 0.0 & 65.2 & 40.7 & 38.4 & 76.2 & 67.9 & 40.9 & 64.3 \\
\hline $\mathrm{Al}_{2} \mathrm{O}_{3}$ & 8.5 & 17.4 & 0.0 & 0.0 & 0.0 & 0.0 & 22.9 & 0.0 & 0.0 & 22.3 & 23.1 & 0.0 & 22.1 \\
\hline $\mathrm{Cr}_{2} \mathrm{O}_{3}$ & 60.6 & 0.0 & 0.0 & 0.0 & 0.0 & 0.0 & 0.0 & 0.0 & 0.0 & 0.0 & 0.0 & 0.0 & 0.0 \\
\hline $\mathrm{FeO}$ & 31.0 & 9.4 & 19.3 & 3.8 & 24.3 & 0.0 & 0.0 & 21.2 & 24.6 & 0.0 & 0.0 & 21.7 & 0.0 \\
\hline MgO & 0.0 & 11.9 & 41.5 & 0.0 & 35.0 & 0.0 & 0.0 & 38.1 & 37.0 & 0.0 & 0.0 & 37.3 & 0.0 \\
\hline $\mathrm{CaO}$ & 0.0 & 1.2 & 0.0 & 0.0 & 0.0 & 51.5 & 2.2 & 0.0 & 0.0 & 0.0 & 2.2 & 0.0 & 2.2 \\
\hline $\mathrm{Na}_{2} \mathrm{O}$ & 0.0 & 0.0 & 0.0 & 0.0 & 0.0 & 0.0 & 6.1 & 0.0 & 0.0 & 1.5 & 6.2 & 0.0 & 10.5 \\
\hline $\mathrm{K}_{2} \mathrm{O}$ & 0.0 & 0.0 & 0.0 & 0.0 & 0.0 & 0.0 & 3.6 & 0.0 & 0.0 & 0.0 & 0.6 & 0.0 & 0.9 \\
\hline $\mathrm{P}_{2} \mathrm{O}_{5}$ & & & & & & 48.5 & & & & 0.0 & 0.0 & & \\
\hline Total & 100.0 & 100.0 & 100.0 & 100.0 & 100.0 & 100.0 & 100.0 & 100.0 & 100.0 & 100.0 & 100.0 & 100.0 & 100.0 \\
\hline \multicolumn{14}{|c|}{ Structural formulae } \\
\hline $\mathrm{Si}$ & 0.0 & & 1.0 & & & 0.0 & 11.5 & 1.0 & 1.0 & & 11.7 & 1.1 & 11.4 \\
\hline Al & 2.8 & & 0.0 & & & 0.0 & 4.8 & 0.0 & 0.0 & & 4.7 & 0.0 & 4.6 \\
\hline $\mathrm{Cr}$ & 13.6 & & 0.0 & & & 0.0 & 0.0 & 0.0 & 0.0 & & 0.0 & 0.0 & 0.0 \\
\hline $\mathrm{Fe}$ & 7.4 & & 0.4 & & & 0.0 & 0.0 & 0.5 & 0.5 & & 0.0 & 0.5 & 0.0 \\
\hline $\mathrm{Mg}$ & 0.0 & & 1.6 & & & 0.0 & 0.0 & 1.5 & 1.5 & & 0.0 & 1.4 & 0.0 \\
\hline $\mathrm{Ca}$ & 0.0 & & 0.0 & & & 19.6 & 0.4 & 0.0 & 0.0 & & 0.4 & 0.0 & 0.4 \\
\hline $\mathrm{Na}$ & 0.0 & & 0.0 & & & 0.0 & 2.1 & 0.0 & 0.0 & & 2.1 & 0.0 & 3.6 \\
\hline K & 0.0 & & 0.0 & & & 0.0 & 0.8 & 0.0 & 0.0 & & 0.1 & 0.0 & 0.2 \\
\hline P & 0.0 & & 0.0 & & & 14.6 & 0.0 & 0.0 & 0.0 & & 0.0 & 0.0 & 0.0 \\
\hline
\end{tabular}

Olivine-the structural formula was calculated on the basis of 4 oxygen. Chromite and plagioclase-the structural formula was calculated on the basis of 32 oxygen. Phosphate-the structural formula was calculated on the basis of 56 oxygen 
Table 2 Summary of mineralogic properties of the adhering grains

\begin{tabular}{|c|c|c|c|c|c|}
\hline Figure & Adhering particle & Mineralogy & Size & Impact residue & Notes \\
\hline $\begin{array}{l}\text { Fig. 4a } \\
\text { (left grain) }\end{array}$ & $\begin{array}{l}\text { RB-DQ04-0062 } \\
\text { (Naoko) }\end{array}$ & Chromite & $750 \times 320 \mathrm{~nm}$ & No & $\begin{array}{l}\text { Host olivine and the chromite are a } \\
\text { lithic fragment }\end{array}$ \\
\hline $\begin{array}{l}\text { Fig. 4a } \\
\text { (right grain) }\end{array}$ & $\begin{array}{l}\text { RB-DQ04-0062 } \\
\text { (Naoko) }\end{array}$ & $\begin{array}{l}\text { Aggregate of glassy Si-rich } \\
\text { material and troilite }\end{array}$ & $380 \times 215 \mathrm{~nm}$ & No & Itokawa-like material \\
\hline Fig. 4b & $\begin{array}{l}\text { RB-DQ04-0091 } \\
\text { (Mizuki) }\end{array}$ & $\mathrm{SiO}_{2}$ glass & $1.5 \times 0.4 \mu \mathrm{m}$ & Yes & Porous grain \\
\hline $\begin{array}{l}\text { Fig. } 4 c \\
\text { (left grain) }\end{array}$ & $\begin{array}{l}\text { RB-DQ04-0091 } \\
\text { (Mizuki) }\end{array}$ & Low-Ca pyroxene $\left(E n_{73}\right)$ & $350 \times 150 \mathrm{~nm}$ & No & Itokawa-like material \\
\hline $\begin{array}{l}\text { Fig. } 4 c \\
\text { (right grain) }\end{array}$ & $\begin{array}{l}\text { RB-DQ04-0091 } \\
\text { (Mizuki) }\end{array}$ & Carbon & $\sim 110 \mathrm{~nm}$ & No & Contamination? \\
\hline Fig. $4 d$ & $\begin{array}{l}\text { RB-DQ04-0091 } \\
\text { (Mizuki) }\end{array}$ & Phosphate & $1 \times 0.4 \mu \mathrm{m}$ & Yes & $\begin{array}{l}\text { Likely ejecta from a micrometeoroid } \\
\text { impact }\end{array}$ \\
\hline $\begin{array}{l}\text { Fig. 4e } \\
\text { (left grain) }\end{array}$ & $\begin{array}{l}\text { RB-DQ04-0062 } \\
\text { (Naoko) }\end{array}$ & Olivine $\left(\mathrm{Fa}_{21}\right)$ & $900 \times 340 \mathrm{~nm}$ & Yes & $\begin{array}{l}\text { Planar crystallographic deformation } \\
\text { features }\end{array}$ \\
\hline $\begin{array}{l}\text { Fig. } 4 \mathrm{e} \\
\text { (middle grain) }\end{array}$ & $\begin{array}{l}\text { RB-DQ04-0062 } \\
\text { (Naoko) }\end{array}$ & $\begin{array}{l}\text { Aggregate of Fe metal } \\
\text { and S-rich material }\end{array}$ & 300 nm in length & Yes & Lack of $\mathrm{Ni}$ in the Fe metal grain \\
\hline $\begin{array}{l}\text { Fig. 4e } \\
\text { (right grain) }\end{array}$ & $\begin{array}{l}\text { RB-DQ04-0062 } \\
\text { (Naoko) }\end{array}$ & $\begin{array}{l}\text { Glassy } \mathrm{SiO}_{2} \text { with variable amounts } \\
\text { of } \mathrm{FeO} \text { and } \mathrm{MgO} \text { (see Table 1) }\end{array}$ & 340 nm in length & Yes & $\begin{array}{l}\text { Porous grain. Beam damage at the } \\
\text { contact with the host grain }\end{array}$ \\
\hline Fig. $4 f$ & $\begin{array}{l}\text { RB-DQ04-0091 } \\
\text { (Mizuki) }\end{array}$ & Plagioclase $\left(A n_{12} A_{6} b_{62}\right)$ & $1.5 \times 1 \mu \mathrm{m}$ & No & Itokawa-like material \\
\hline
\end{tabular}

the Muses-C region on Itokawa was relatively stable at millimeter to centimeter-depths for the last $\sim 10^{5}$ years (e.g., Berger and Keller 2015). However, this does not preclude the movement and fracturing of grains in the uppermost $\sim 100 \mu \mathrm{m}$ of regolith that is required by our observations. The dynamics of the upper regolith could be driven by micrometeoroid impact or electrostatic repulsion between particles (Lee 1996; Hartzell and Scheeres 2013).

We found several splash-melt features on the two Hayabusa particles, including two large features more than a few micrometers in size. The presence of splash

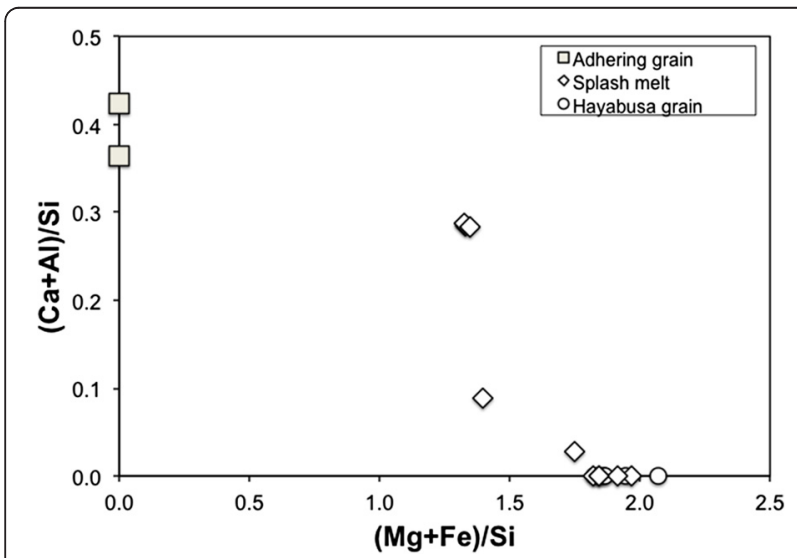

Fig. 6 The atomic element ratios of $(\mathrm{Ca}+\mathrm{Al}) / \mathrm{Si}$ vs. $(\mathrm{Mg}+\mathrm{Fe}) / \mathrm{Si}$ in the splash melt (white diamonds), adhering particle (gray squares), and Itokawa particles (white circles) shown in Fig. 5 melt on blister-free surfaces indicates that at least some of the splash melts have been deposited within the last few thousand years. With a statistical survey of the degree of blistering and presence of splash melts, it would be possible to roughly estimate the micrometeoroid flux on Itokawa over the last several thousand years. The splash melt features are relatively thin and scarce compared to even immature lunar soil regolith grains of similar size, which are usually covered with thick, beaded splash melt (Fig. 7). One of the splash melts had a chemical composition distinct from the grain it was lying on, with significant mixing between the melt and the host grain. Using the Stefan-Boltzmann law (see equations below), we calculate that the time for a $2 \mu \mathrm{m}$ olivine grain (about the volume of our largest splashmelt) to cool from $T_{\text {initial }}=3000{ }^{\circ} \mathrm{C}$ to $T_{\text {final }}=1700{ }^{\circ} \mathrm{C}$ to be about $200 \mu \mathrm{s}$. A grain ejected at $10 \mathrm{~km} / \mathrm{s}$ will travel about $2 \mathrm{~m}$ in this time.

$$
\frac{d E}{d t}=\epsilon \sigma A\left(T_{\text {hot }}^{4}-T_{\text {ambinent }}^{4}\right) \approx \epsilon \sigma A T_{\text {hot }}^{4}
$$

where $\epsilon$ is the emissivity, $\sigma$ is the Stefan-Boltzmann constant, $A$ is the surface area, $T$ is the temperature in Kelvin. Additionally:

$$
d E=c m d T
$$

where $c$ is the specific heat capacity, $m$ is the mass.

$$
\frac{d E}{d t}=\frac{d E}{d T} \frac{d T}{d t}
$$




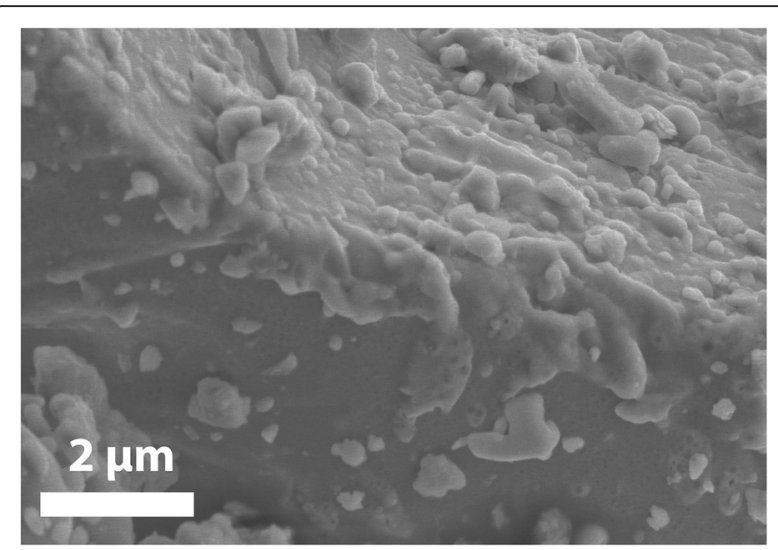

Fig. 7 Secondary electron image of a section of a 30 $\mu \mathrm{m}$ Apollo 16 lunar soil grain (from 61221, an immature lunar regolith sample) with thick, beaded splash melt

$$
\begin{aligned}
& \epsilon \sigma A T^{4}=c m \frac{d T}{d t} \\
& d t=\frac{c m}{\epsilon \sigma A T^{4}} d T \\
& t_{\text {cooling }}=\frac{c m}{\epsilon \sigma A} \int_{T_{\text {initial }}}^{T_{f \text { inal }}} \frac{d T}{T^{4}}=\frac{c m}{3 \epsilon \sigma A}\left(\frac{1}{T_{\text {initial }}^{3}}-\frac{1}{T_{\text {final }}^{3}}\right)
\end{aligned}
$$

So, the splash melts we see on the Hayabusa particles could have been excavated from, at most, $2 \mathrm{~m}$ away. Grains that appear to have been partially molten when they impacted, such as the $\sim 1.5 \mu \mathrm{m}$ grain in Fig. 2c, came from close to this limit (in this case, $3 \mathrm{~m}$ ). The splash melts and partially molten adhering particles can be used to probe the composition of regolith a few meters away from the host grain. Both the splash melt in Fig. 2a and adhering grain with melt streaks in Fig. 2c have composition consistent with Itokawa but inconsistent with their immediate host grain, implying that it could have been transported from meters away.

Nakamura (2012) stated that the adhering particles are fragments of larger grains on Itokawa's surface, and that they are probably formed by impacts. With our detailed FIB-TEM analyses of several of these adhering grains on the two Hayabusa particles, we are able to test this hypothesis and differentiate between adhering grains that are and are not the direct result of impacts.

Some of the impact-generated material on Itokawa will be lost to space due to the asteroid's low surface gravity. However, impact residue that is ejected with a large enough component of its velocity towards another face of the asteroid can travel a long distance and remain on Itokawa. This distance can be much greater than the size of the crater generated by the impact, which were observed to be centimeter-sized on Itokawa (Miyamoto et al. 2007). So, it is not surprising that we observed abundant impact- generated material on these Hayabusa particles but no obvious impact craters. The $200 \mathrm{~nm}$ and smaller craters observed by Nakamura (2012) are mysterious as they require 10-20 nm impactors (beta meteoroids) accelerated to very high velocities, which is impossible to do by radiation pressure.

The other adhering grains we identified as impact residue showed evidence of their formation. A shocked olivine grain is relatively intact, and is consistent with the grain it is sitting on (but again, no impact crater was found, so it must have been transported from at least $50 \mu \mathrm{m}$ away). The $\mathrm{SiO}_{2}$ amorphous grains with melt-droplet texture, and nearby Ni-free metallic Fe imply that these condensed from vaporized Fe-bearing silicate. Sub-micron metallic Fe, like the particle we observed, can have an effect on the spectral darkening of Itokawa (Lucey and Riner 2011).

The loosely attached local regolith and lithic fragments we observed are likely the result of regolith gardening (fracturing and movement of small surface grains) on Itokawa, as also evidenced by the highly variable solarwind blistering.

We did not identify any grains that were of definitively non-Itokawa like composition. This is also not surprising considering the ratio of the excavated crater volume to the projectile volume is $\sim 1000$.

The typical contaminants described so far among the Itokawa particles are metallic $\mathrm{Al}$, tin oxide, quartz particles, and probably carbonaceous particles (Noguchi et al. 2014; Uesugi et al. 2014). Only one of the ten adhering grains we analyzed was possibly contamination, the Crich grain shown on the right of Fig. 4c.

Half of the adhering grains (five of ten) we measured in detail were clearly the direct result of micrometeoroid impacts (Tables 1 and 2). We could not make this distinction without removing the adhering grains by FIB and analyzing them by TEM. These five impact-created adhering grains, along with the splash melt features we see, tell us that the very outer surface of Itokawa regolith was significantly modified by micrometeoroid impacts.

\section{Abbreviations \\ EDS: energy-dispersive X-ray spectroscopy; FEG: field emission gun; FIB: focused ion beam; HAADF-STEM: high-angle annular dark-field scanning transmission electron microscopy; HIM: helium ion microscope; SEM: scanning electron microscope; TEM: transmission electron microscope.}

\section{Competing interests}

The authors declare that they have no competing interests.

\section{Authors' contributions}

ED contributed to the FIB/TEM observations. RO acquired the HIM images. The manuscript was prepared by ED and RO. All authors read and approved the final manuscript.

\section{Acknowledgements}

We thank the editor and two anonymous reviewers for their insightful and constructive comments that helped to improve this manuscript. This work was funded by NNX14AF24G to R. C. Ogliore and by NNX11AK51G to A. J. Brearley. The helium ion microscopy was performed using the Environmental 
Molecular Sciences Laboratory, a Department of Energy Office of Science User Facility, sponsored by the Office of Biological and Environmental Research and located at Pacific Northwest National Laboratory. Sample preparation (focused ion beam) and transmission electron microscopy analysis were carried out in the Electron Microbeam Analysis Facility in the Department of Earth and Planetary Sciences and Institute of Meteoritics, University of New Mexico.

\section{Author details}

'Department of Earth and Planetary Sciences MSC03-2040, 1 University of New Mexico, Albuquerque, NM 87131-0001, USA. ²Department of Physics, Washington University in St. Louis, St. Louis, MO 63117, USA.

Received: 1 May 2015 Accepted: 15 January 2016

Published online: 13 February 2016

\section{References}

Assonov SS, Biryukov AY, Kashkarov LL, Nevzorov VN, Semenova AS and Shukolyukov YA(1998) Vesiculation in silicate grains of Luna-16 soil. (abstract \#1635). 29th Lunar and Planetary Science Conference

Berger EL and Keller LP (2015) Space weathering of Itokawa particles: implications for regolith evolution. (abstract \#2351). 46th Lunar and Planetary Science Conference

Clark BE, Hapke B, Pieters C, Britt D (2002) Asteroid space weathering and regolith evolution. In: Bottke W, Cellino A, Paolicchi P, Binzel RP (eds) Asteroids III. The University of Arizona Press, Tucson, Arizona, pp 585-599

Gaffey MJ, Bell JF, Cruikshank DP, Gehrels T, Matthews MS (1989) Reflectance spectroscopy and asteroid surface mineralogy. In: Binzel RP, Gehrels T, Matthews MS (eds) Asteroids II. The University of Arizona Press, Tucson, Arizona, pp 98-127

Hartzell CM, Scheeres DJ (2013) Dynamics of levitating dust particles near asteroids and the Moon. J Geophys Res (Planets) 118:116-125

Hirata N, Barnouin-Jha OS, Honda C, Nakamura R, Miyamoto H, Sasaki S, Demura H, Nakamura AM, Michikami T, Gaskell RW, Saito J (2009) A survey of possible impact structures on 25143 Itokawa. Icarus 200:486-502

Kaletta D (1980) Light element implantations in metals. Radiat Eff 47:237-251

Keller LP, McKay DS (1997) The nature and origin of rims on lunar soil grains. Geochim Cosmochim Acta 61:2331-2341

Langenhorst F (2002) Shock metamorphism of some minerals: basic introduction and microstructural observations. Bulletin of the Czech Geological Survey 77: 265-282

Langenhorst F, Harries D, Pollok K, van Aken PA (2014) Mineralogy and defect microstructure of an olivine-dominated Itokawa dust particle: evidence for shock metamorphism, collisional fragmentation, and LL chondrite origin. Earth Planets Space 66:118

Lee $P$ (1996) Dust levitation on asteroids. Icarus 124:181-194

Lucey PG, Riner MA (2011) The optical effects of small iron particles that darken but do not redden: evidence of intense space weathering on Mercury. Icarus 212:451-462

Matsumoto T, Tsuchiyama A, Miyake A., Noguchi T, Nakamura T, Nakamura M, Matsuno J, Shimada A, Uesugi K and Nakano T (2014) Surface micromorphologies of regolith particles from asteroid Itokawa and its implication to space weathering. (abstract 5130). 77th Meeting of the Meteoritical Society

Miyamoto H, Yano H, Scheeres DJ, Abe S, Barnouin-Jha O, Cheng AF, Demura H, Gaskell RW, Hirata N, Ishiguro M, Michikami T, Nakamura AM, Nakamura R, Saito J, Sasaki S (2007) Regolith migration and sorting on asteroid Itokawa. Science 316:1011

Nakamura E (2012) Space environment of an asteroid preserved on micrograins returned by the Hayabusa spacecraft. Proc Natl Acad Sci 109:624-E629

Nakamura T, Noguchi T, Tanaka M, Zolensky ME, Kimura M, Tsuchiyama A, Nakato A Ogami T, Ishida H, Uesugi M, Yada T, Shirai K, Fujimura A, Okazaki R, Sandford SA, Ishibashi Y, Abe M, Okada T, Ueno M, Mukai T, Yoshikawa M, Kawaguchi J (2011) Itokawa dust particles: a direct link between S-type asteroids and ordinary chondrites. Science 333:1113-1116

Nakashima D, Kita NT, Ushikubo T, Noguchi T, Nakamura T, Valley JW (2013) Oxygen three-isotope ratios of silicate particles returned from asteroid Itokawa by the Hayabusa spacecraft: a strong link with equilibrated LL chondrites. Earth Planet Sci Lett 379:127-136

Noguchi T, Kimura M, Hashimoto T, Konno M, Nakamura T, Zolensky ME, Okazaki R, Tanaka M, Tsuchiyama A, Nakato A, Ogami T, Ishida H, Sagae R, Tsujimoto S,
Matsumoto T, Matsuno J, Fujimura A, Abe M, Yada T, Mukai T, Ueno M, Okada T, Shirai K, Ishibashi Y (2014) Space weathered rims found on the surfaces of the Itokawa dust particles. Meteorit Planet Sci 49:188-214

Thompson MS, Christoffersen R, Zega TJ, Keller LP (2014) Microchemical and structural evidence for space weathering in soils from asteroid Itokawa. Earth Planets Space 66:89-99

Uesugi M, Naraoka H, Ito M, Yabuta H, Kitajima F, Takano Y, Mita H, Ohnishi I, Kebukawa Y, Yada T, Karouji Y, Ishibashi Y, Okada T, Abe M (2014) Sequential analysis of carbonaceous materials in Hayabusa-returned samples for the determination of their origin. Earth Planets Space 66:102-113

Ward B, Notte JA, Economou NP (2007) Helium-ion microscopy. Photonics Spectra 41:68-70

Yurimoto $\mathrm{H}$, Abe K-I, Abe M, Ebihara M, Fujimura A, Hashiguchi M, Hashizume K, Ireland TR, Itoh S, Katayama J, Kato C, Kawaguchi J, Kawasaki N, Kitajima F, Kobayashi S, Meike T, Mukai T, Nagao K, Nakamura T, Naraoka H, Noguchi T, Okazaki R, Park C, Sakamoto N, Seto Y, Takei M, Tsuchiyama A, Uesugi M, Wakaki S, Yada T, Yamamoto K, Yoshikawa M, Zolensky ME (2011) Oxygen isotopic compositions of asteroidal materials returned from itokawa by the Hayabusa mission. Science 333:1116-1119

\section{Submit your manuscript to a SpringerOpen ${ }^{\circ}$ journal and benefit from:}

- Convenient online submission

- Rigorous peer review

- Immediate publication on acceptance

- Open access: articles freely available online

- High visibility within the field

- Retaining the copyright to your article

Submit your next manuscript at $>$ springeropen.com 